\title{
THE CLIMAX FOREST OF ISLE ROYALE, LAKE SUPERIOR, AND ITS DEVELOPMENT. II
}

CONTRIBUTIONS FROM THE HULL BOTANICAL LABORATORY I65

WILLIAM S. COOPER

(WITH SIXTEEN FIGURES)

Part II.-The successions

THE PRIMARY SUCCESSIONS

The xerarch successions

I. Physiographic development of the habitats and description

of present shores

The physiographic development of the shore habitats is in large part that of the island itself, which has been briefly outlined in the introduction. Since the postglacial history of Isle Royale has been one of gradual emergence from the waters of Lake Duluth and its successors, it follows that all parts of the island have at some stage of the process been shore.

The present shores of Isle Royale may be classified in several ways. First, there are the rock shores and the beaches, of which the former are vastly the more important. The rock shores may be classified in three ways: according to degree of slope, degree of shelter, and kind of rock involved. According to slope we find two classes: cliff shores and gently sloping shores. These two types are usually sharply distinguished. The cliffs are characteristic of the northwest coast of the island and of its surrounding islets, being produced by the broken edges of the lava and sedimentary layers; while on the southeast coast, the slope of the shores corresponds rather closely with the dip of the rocks, which is nearly everywhere gentle, averaging perhaps $10-15^{\circ}$. The cliffs range from I to $20 \mathrm{~m}$. or more in height, are frequently perpendicular, and may sometimes be seen to descend without a break to considerable depths below the surface of the water. According to degree of exposure the shores, both cliff and sloping, may be divided II5]

[Botanical Gazette, vol. 55 
into those exposed to the lake winds and waves, and those protected from them. In classifying according to kind of rock, the physical, not the chemical, characteristics are the important ones. The rocks of Isle Royale are partly volcanics, which are resistant, and subordinately sedimentaries (sandstones and conglomerates), which are much less so. On the southeast coast of the island the shores, where of volcanic rock, have smooth sloping surfaces, and where composed of sandstone or conglomerate are often much broken and

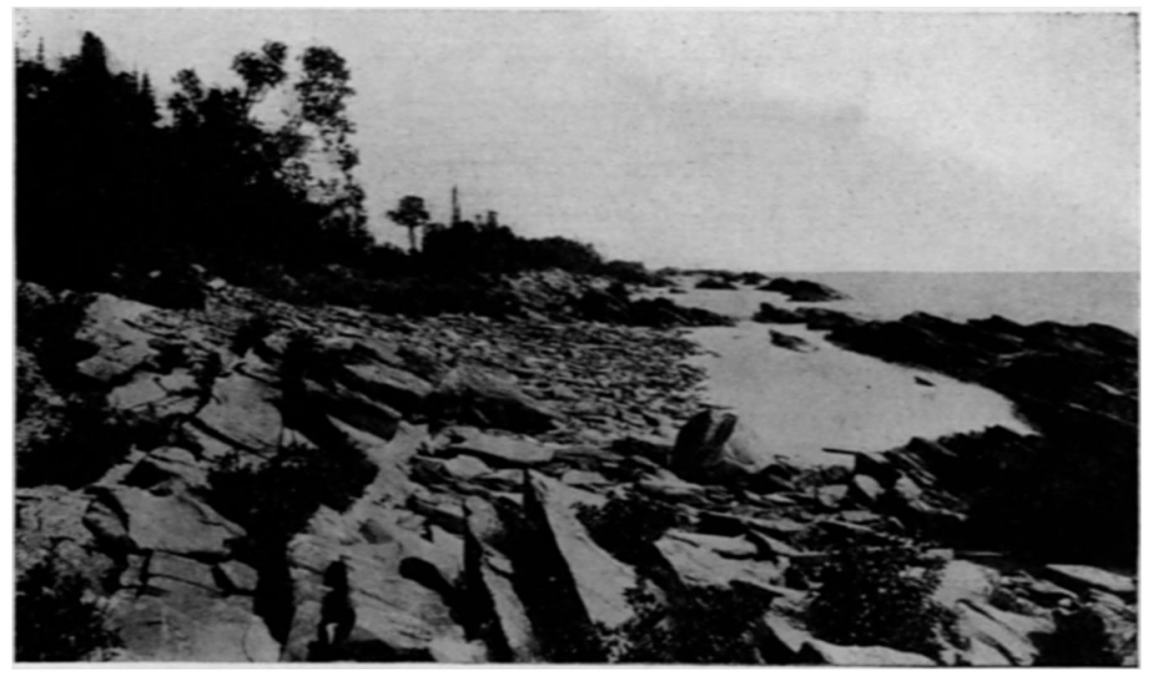

FIG. 15.-Outer shore of Long Ishand, southeast of Siskowit Bay: sandstone beds dipping southeast; a glacial bowlder of granite in the foreground; notable disintegration of the sedimentary rock is exhibited; the forest extends low down because the force of the waves is broken by irregularities of the shore (cf. fig. 27, where the degree of exposure is the same).

very irregular (compare figs. 24 and 15 ). Striking differences in rate of erosion were noted on the northwest coast. Near Blake Point the great "Greenstone" layer, which forms the backbone of Isle Royale, is at the shore, and forms smooth cliffs which rise direct from the water to a height of $20 \mathrm{~m}$. or more. The stable character of these cliffs is shown by the thick coating of lichens which covers them, the belt of brilliant orange Placodium being especially conspicuous. Trees of large size, as well as many smaller 
plants, are abundant in the crevices (fig. 16). Very different is the shore just southwest of McCargoe's Cove (Sec. 23, T. 66 N., R. 35 W.). The material here is a sandstone, and the cliff is being rapidly eroded by the waves. Lichens are absent, and the soil and forest growth at the top are being undermined. Several recently overturned trees were seen. On the whole, wave erosion at the present lake level has not yet notably modified the configuration of the coast, so that shore recession need not be reckoned with as an important influence upon the vegetation.

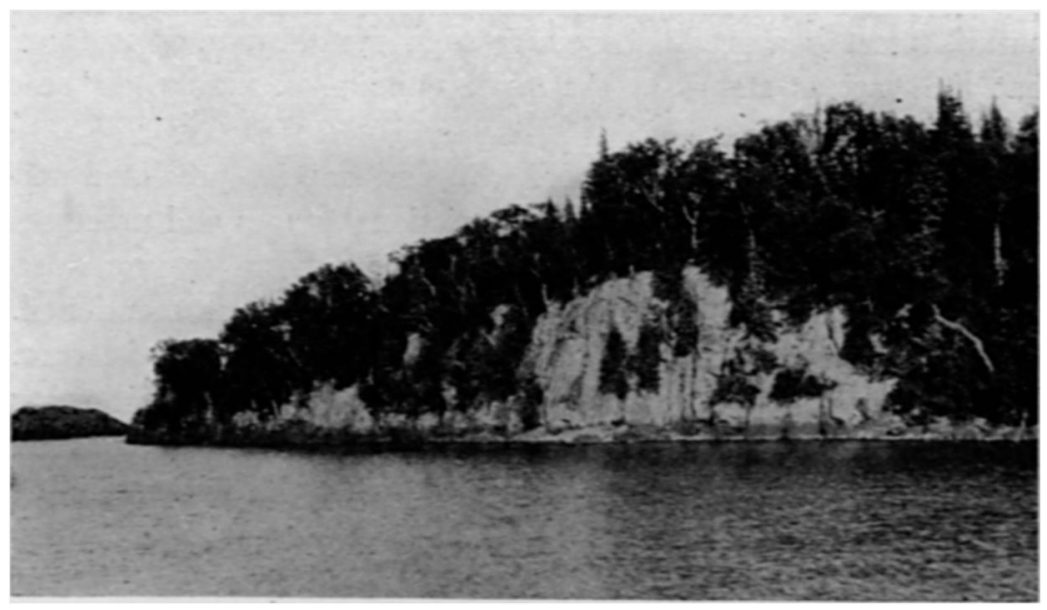

Fic. 16.-Inward-facing cliff of one of the small islands bounding Rock Harbor on the southeast: resistant volcanic rock produces stable cliffs; because of sheltered lecation the limit of forest extension is near the water's edge, but the trees are confined to ledges and crevices.

\section{The rock shore succession}

With regard to the comparative areas which have been vegetated through the instrumentality of the various successions, both hydrarch and xerarch, the rock shore succession is by far the most important of all. A conservative estimate would indicate that at least nine-tenths of the forest of Isle Royale has developed along the line of this succession. At the same time it is a comparatively simple one, and will not require extended treatment.

The fundamental fact in the process, throughout the history 
of the island, has been the occupation by vegetation of new areas left exposed by the retreating waters. Recession has now ceased, temporarily at least, and no fresh surfaces have been presented for a long period of time. The forest in its advance has for this reason in some places practically reached the limit of possible growth, being prevented from further extension by wave and ice action. In these places the forest is seen extending in its full development to a line where it ends abruptly, being separated from the water by a strip of nearly bare rock shore. At other points invasion is still actively in progress, and the transition from bare shore to mature forest is a gradual one. It is in such situations as these that the various stages in the succession are seen in their best development.

On all the types of rock shore, cliff and sloping, protected and exposed, of all kinds of rock, the successional stages and processes are in general essentially the same. There are, however, important modifications due to the differences in habitat just mentioned. Among them are telescoping, suppression, or elimination of certain stages, and variations in rapidity of invasion. In the following paragraphs the complete series of stages which constitute the rock shore succession will be first described, with the understanding that rarely will this series be found in absolute entirety. Afterward the modifications of the series associated with the different types of rock shores will be discussed.

\section{a) The complete series}

In tracing the early stages of the rock shore succession we find three separate lines of advance, which may conveniently be termed subsuccessions. They are the rock surface subsuccession, the crevice subsuccession, and the rock pool subsuccession. Later these unite, and the development proceeds thenceforth along a single line.

I. The rock surface subsuccession.-We have here mainly a study in the ecology of lichens, to which adequate treatment can be given only by a specialist in that group. The general sequence of stages has been frequently described in ecological papers, as by WHITFORD (59) for the southern shore of Lake Superior. Crustose lichens are the first plants to appear, and are accompanied by xero- 
phytic mosses, principally Grimmia coata Web. and Moore. A brilliant orange band of the lichen Placodium is a prominent feature of cliffs, its lower edge $2 \mathrm{~m}$. above the water. This band is also distinguishable, though much less prominent, on the sloping shores. Next come foliose lichens, with the mosses Hedwigia albicans (Web.) Lindb. and Orthotrichum anomalum Hedw., and finally appear the fruticose forms, prominent among them the three large species of Cladonia, C. rangiferina Web., C. syloatica (C.) Hoffm., and $C$. alpestris L.; also species of Stereocaulon (fig. I7).

The conditions on these bare surfaces are obviously severe, and without the aid of crevice plants vegetation advances very slowly upon them. Below they are frequently swept clean by the waves, and above, the wash of the rain keeps them clear of all débris except that of large size. Only in hollows can any gravel or humus accumulate, and only in such places does any moisture remain. As the lichen vegetation increases in bulk, soil and moisture are more and more conserved, and occasional herbs and low shrubs, and even trees, come in. Where there are few or no crevices, however, the process is

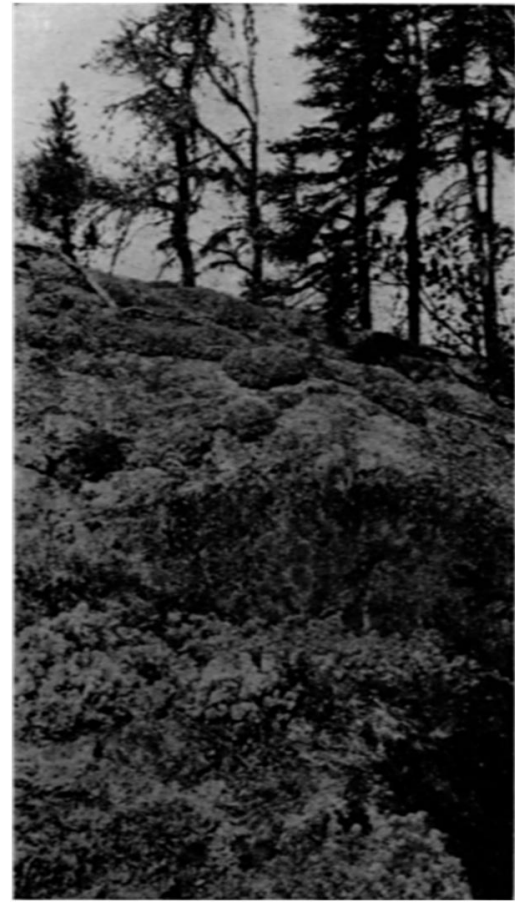

Fig. 17.-Rock surface at Chippewa Harbor partially covered with a mat of cladonias; paucity of crevices resulting in very slow invasion; jack pines, pioneers of the rerophytic forest stage, in the background at the left. so slow that such areas frequently become surrounded by mature forest, though the vegetation upon them may not have advanced as far as the heath-mat stage. Such "rock openings" are common in the forest upon the lower ridges. One of them, near Siskowit Lake (Sec. 32, T. 65 N., R. 35 W.), deserves description and illustration (fig. 18). 
This opening was about $50 \mathrm{~m}$. long by half as wide, and was surrounded by the climax forest, which ended rather abruptly at its edge. The surface of the rock was very smooth, little weathered, with very few crevices. A mat composed of mosses and cladonias covered it except for scattered irregular areas which bore only a few foliose and crustose lichens. The mat had started from numerous centers, forming at first more or less circular patches which later had partially coalesced. The thickest portions were composed principally of Cladonia rangiferina, $C$. syloatica, and

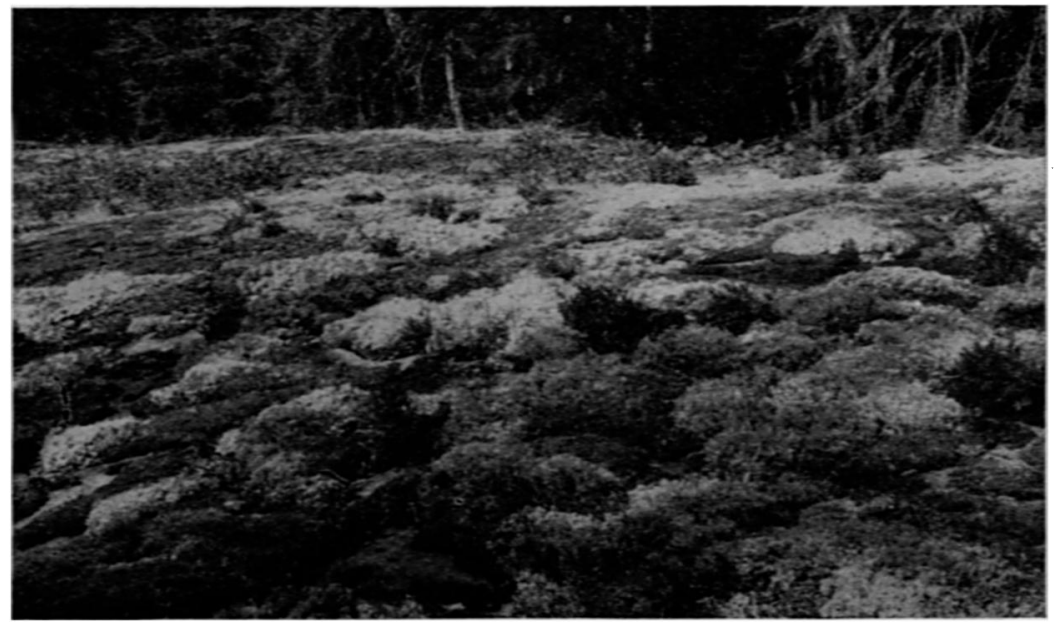

Fig. 18.-Rock opening in the climax forest near Siskowit Lake: cladonias (lighter patches) are dominant; masses of the moss Rhocomitrivm (darker areas) border the Cladomia patches; a few small areas of bare rock; Cryplogramime acrostichoides and other plants growing upon the mat.

C. alpestris, and around the edges of the patches and making up the thinner portions was a growth of the moss Rhacomitrium canescens ericoides (Web.) Schimp. Growing upon the thicker portions were scattered plants of Cryptogramme acrostichoides, Dieroilla, Arctostaphylos, and a few others. The whole mat could be lifted from the rock, there being absolutely no connection except where the younger plants of the moss (Rhacomitrium) were feebly attached. This species was evidently the pioneer, and the cladonias later had become superimposed upon it. From this area we learn that a 
luxuriant mat of vegetation may form upon a bare rock surface without the aid of crevice plants. The process, however, is exceedingly slow, and the mat thus formed is not so firmly attached and so surely permanent as that which is bound together by the trailing stems from the crevices.

2. The creoice subsuccession.-Crevices due to bedding planes, joints, and to differential weathering occur more or less commonly in all the rocks of Isle Royale. Where they are abundant the stages of the rock shore succession are passed through rapidly; where they are rare the process moves slowly. The soil which forms

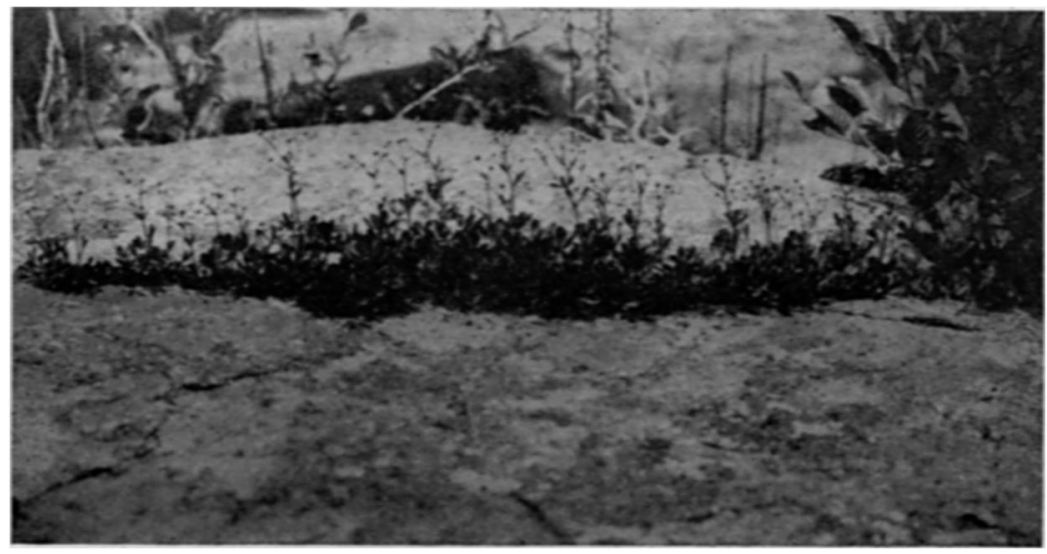

Fic. 19.-Polentille tridentale as a crevice plant; outer shore of Mott Island

in the crevices through disintegration of the rock, or is washed into them from the surrounding surfaces and the forest above, or is carried to them by the wind, is held within them, at least in part. Water flowing into or through the crevices also is retained. They form natural collecting places for seeds carried by wind, birds, and surface wash. Thus it is not surprising that nearly every crevice, large or small, is peopled by plants of many kinds. The number of species found growing as crevice plants is very great, and includes forms ordinarily occurring in diverse habitats. There are listed in my field notes 100 species, or one-fifth of the recorded flora of Isle Royale, as growing in crevices upon rock shores, and this list includes such forest plants as Maianthemum canadense, 
Cornus canadensis, Clintonia borealis, Mitella nuda; and such bog forms as Andromeda glaucophylla, Ledum groenlandicum, Aspidium Thelypteris, and Drosera rotundifolia. Aside from these incidental occurrences, there is a group of species that inhabit crevices on the shores everywhere and which are rarely found in other habitats. By far the most important of the early arrivals on account of its abundance and densely tufted growth is Potentilla tridentata Ait. (three-toothed cinquefoil) (fig. I9). Other noteworthy pioneers are Campanula rotundifolia L. (bluebell), Solidago hispida Muhl. (goldenrod), Achillea Millefolium L. (yarrow), Aster ptarmicoides T. \& G., Saxifraga tricuspidata Rottb. (three-toothed saxifrage), Deschampsia caespitosa (L.) Beauv. (hair grass), Trisetum spicatum (L.) Richter. Another group of plants deserves mention. These inhabit moist sheltered crevices and are also characteristic of the margins of rock pools. They are Primula mistassinica Michx., Pinguicula vulgaris L. (butterwort), Selaginella selaginoides (L.) Link, Lycopodium Selago L., Polygonum viviparum L. (alpine buckwheat), Tofieldia palustris Huds. (false asphodel), T. glutinosa (Michx.) Pers., Parnassia palustris L. (grass of Parnassus), $P$. parviflora DC, Carex atrata L. var. ovata (Rudge) Boott, C. bicolor All., C. Halleri Gunn., C. paupercula Michx. var. pallens Fernald, Allium Schoenoprasum L. var. sibiricum (L.) Hartm., Empetrum nigrum L. (crowberry), Euphrasia arctica Lange (eyebright), Prenanthes racemosa Michx. (rattlesnake root), Calamagrostis hyperborea Lange. Especially characteristic of moist cliffs are the mosses Swartzia montana (Lamk.) Lindb., Tortula ruralis (L.) Ehrh., Encalypta procera Bruch, E. ciliata (Hedw.) Hoffm. The result of occupation by these classes of plants is the accumulation of humus, with the accompanying decomposition of the adjacent rock.

With these plants, or usually somewhat later, come in certain low shrubs, among them two blueberries (Vaccinium uliginosum L. and $V$. pennsylvanicum Lam.). More important than these, in fact most important of all the crevice plants, are the trailing shrubs, the two junipers (Juniperus horizontalis Moench and $J$. communis L. var. depressa Pursh) and the bearberry (Arctostaphylos Uva-ursi (L.) Spreng.). With them should be included, although it 
is ordinarily a tree, the arbor vitae (Thuja occidentalis L.), which frequently sprawls over the shore rocks after the manner of a prostrate vine.

Finally the trees also appear as crevice plants, and not always last in time, for young seedlings and even aged but stunted individuals are often found inhabiting the same crevice with the earliest herbaceous pioneers. Sometimes the largest cracks are lined with fair-sized trees while the rock surfaces between them are inhabited only by foliose lichens and cladonias. Any tree species may be a crevice pioneer, but Betula alba var. papyrifera occurs most frequently, with Pyrus americana, Thuja occidentalis, and Abies balsamea next in abundance. Growth in early years is sometimes of average rapidity, but the severe conditions soon make themselves felt, and those trees that survive increase in size very slowly. A white spruce I $\mathrm{m}$. high and $8.75 \mathrm{~cm}$. thick was found to be 87 years old, and a balsam of the same height but only $7.5 \mathrm{~cm}$. thick showed an age of 123 years.

The preeminent importance of this subsuccession in the development of the forest should be emphasized. Through the soil and moisture-conserving capacity of the crevices and the resulting abundance and variety of their vegetation, and particularly because of the presence of creeping mat-forming shrubs, the establishment of the climax forest is very much hastened.

3. The rock pool subsuccession.-Much less important than the two preceding, but nevertheless contributing somewhat to the development of the forest by reason of the considerable amount of humus formed through its agency, is the rock pool subsuccession. Depressions of all shapes and sizes are common upon the rock shores (fig. 20). When they are of such a form as to contain standing water, the establishment of vegetation in them is quite different from that displayed in the crevices or upon the rock surfaces. Rain and waves furnish the water, which is frequently only temporarily present. The subsuccession is thus hydrarch in general but its development is subject to interruptions due to partial or entire desiccation. In the smaller depressions, which usually contain water only part of the time, vegetation when present is of the crevice type. In the larger basins which contain 
pools that are nearly or quite permanent, the development is truly hydrarch; and zonation like that found in bogs, but of a simpler type, is usual. On account of the shallowness of the water the bog mat is seldom floating. By far the most important plant in the subsuccession is Scirpus caespitosus L., which starting its growth at the water's edge gradually fills the pools with its dense hard stools. Frequently by growing across the high water outlet it raises the level considerably. Other species are occasionally more important in filling the pools. For instance, one depression was found to be partially filled by a mat composed of Polytrichum

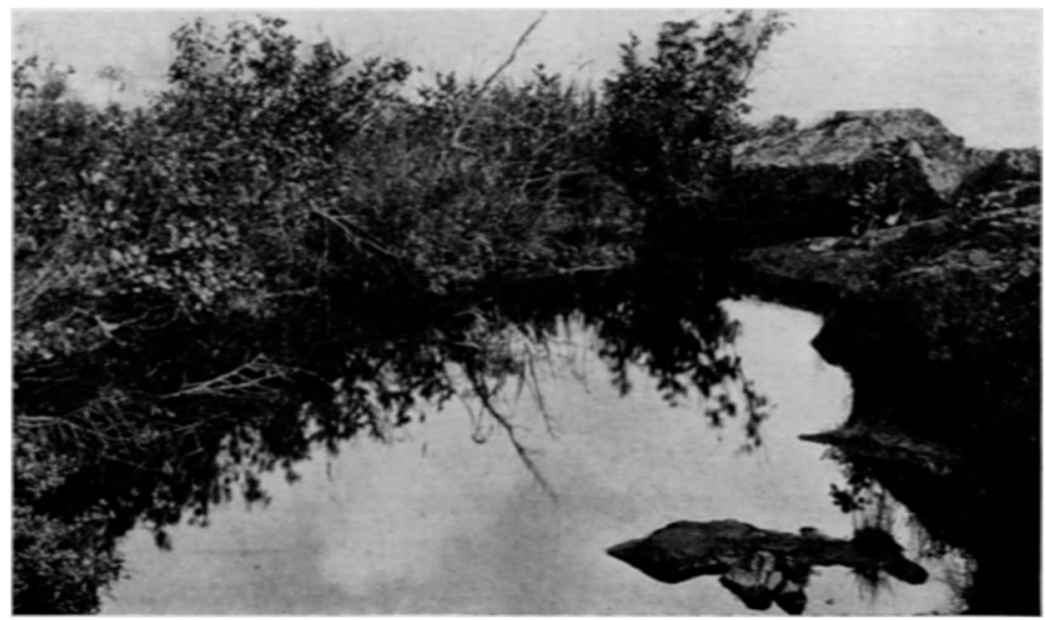

Fic. 20.-Rock pool upon one of the islands bounding Rock Harbor on the southeast: Scirpus coespitosus at the right; Andromedo and Alnus crispa at the left.

commane L. and Aulacomenium palustre (L.) Schwaegr., bound together by the roots and rhizomes of plants growing upon it, among them Potentilla tridentata, Iris versicolor, Vaccinium penusylvaricum. Another pool was being invaded by a mass of Climacium americanum Brid. Upon the turf mat habitually lives the interesting group of plants which has already been listed as occurring in moist crevices. Bog plants are frequent, especially Drosera rotundifolia L. and Polytrichum strictum Banks; and numerous crevice plants occur. Following, usually, the building of the turf mat come certain shrubs, the most important being Vaccinium 
uliginosum L. Vaccinium pennsylvanicum, Andromeda glaucophylla, and Alnus crispa also occur commonly. In some pools Andromeda is advancing directly into the water, the turf mat being absent. Calamagrostis canadensis (Michx.) Beauv. is usually a noteworthy companion to the shrubs.

4. The heath mat.-We have now traced the subsuccessions as far as they remain distinct. In the coalescence of the three the species of the crevice series are the active agents. Such plants as Juniperus horizontalis, J. communis var. depressa, Arctostaphylos Uva-ursi, and the krummholz form of Thuja occidentalis send out their trailing stems in all directions from the crevices in which they are anchored, winding through and among the cladonias of the rock surfaces and the various vegetation of the low places that were formerly pools. The continued growth of these three elements produces a firm compact mat, strongly attached in the crevices and depressions.

The history of an area may often be traced by an examination of the successive layers of the vegetation growing upon it. In one place four stages were discovered. Representing the first were scattered plants of Potentilla tridentata and Deschampsia caespitosa growing up through the mat and traceable to crevices in the rock beneath. Second in order was a thick layer of Arctostaphylos spreading over the rock in all directions but rooting in the crevices. The third stage was represented by Juniperus horizontalis growing over the Arctostaphylos; and the fourth by a few plants of the climax forest, among them Aralia nudicaulis and Maianthemum canadense. The order observed here is by no means universal; in fact, Juniperus horizontalis usually precedes Arctostaphylos.

The four important creeping shrubs differ greatly in their effectiveness in mat formation. In the case of Thuja the growth is too open and the branches reach too great an elevation above the surface to favor the accumulation of humus; and the same to a less degree is true of Juniperus communis var. depressa. Juniperus horizontalis by reason of its closely appressed habit is much superior. Arctostaphylos is probably the best of all, since its overlapping leaves almost entirely prevent the washing away of waste from beneath itself and other plants with which it grows. It is also 
very effective as a conserver of moisture. When the soil elsewhere is absolutely dry, that beneath a layer of Arctostaphylos is often found still to contain a high percentage of water.

Vaccinium pennsylvanicum becomes of importance soon after the establishment of the mat, and frequently dominates large areas in which the junipers and Arctostaphylos appear as relicts only.

It must not be understood that there is a distinct belt of heath mat along the entire front of the forest, or even that it is commonly found continuously over very large spaces. It usually occurs in patches more or less united, separated by areas of bare or incompletely covered rock, and with scattered trees, invaders from the forest, growing upon it. Telescoping of stages is very pronounced in the rock shore succession, so that in a limited area we frequently find representatives of the earliest pioneers, the climax forest, and of all stages between.

5. The jack pine-black spruce stage and the establishment of the climax forest.-It seems clear that the climax forest often follows immediately after the establishment of the heath mat. It seems equally certain that in many places a relatively xerophytic forest stage intervenes, in which the species are Pinus Banksiana Lamb. (jack pine) and Picea mariana (Mill) BSP (black spruce). Populus tremuloides Michx. (aspen) is also sometimes present. The conditions which determine the presence or absence of this stage were not discovered. In either case the establishment of the forest consists simply in a gradual increase in the number of trees inhabiting the rocky shores, the early advance being principally along the crevices.

The jack pine-black spruce forest is at the present day rather limited in extent. It was observed in its best development along the southeast coast of the island from the region of Lake Whittlesey to Lea Cove, and along the northwest shore of Rock Harbor for several miles. In other localities transitional stages passing into the climax were seen. Where conditions are most xerophytic Pinus Banksiana is dominant. In such places the trees grow far apart and there is much bare rock visible between them. Cladonias are the characteristic ground cover, C. rangiferina, C. sylvatica, and 
C. alpestris being about equally abundant. There is frequently considerable young growth of Picea mariana beneath the pines. The evidence derived from the examination of numerous localities indicates that such a type of forest will gradually become more mesophytic in character as the vegetation of the forest floor increases in amount and in water-holding capacity. Changes occur in the character as well as in the amount of the undergrowth. Mosses of the climax forest invade the areas dominated by the cladonias, growing around and over the masses of the lichens,

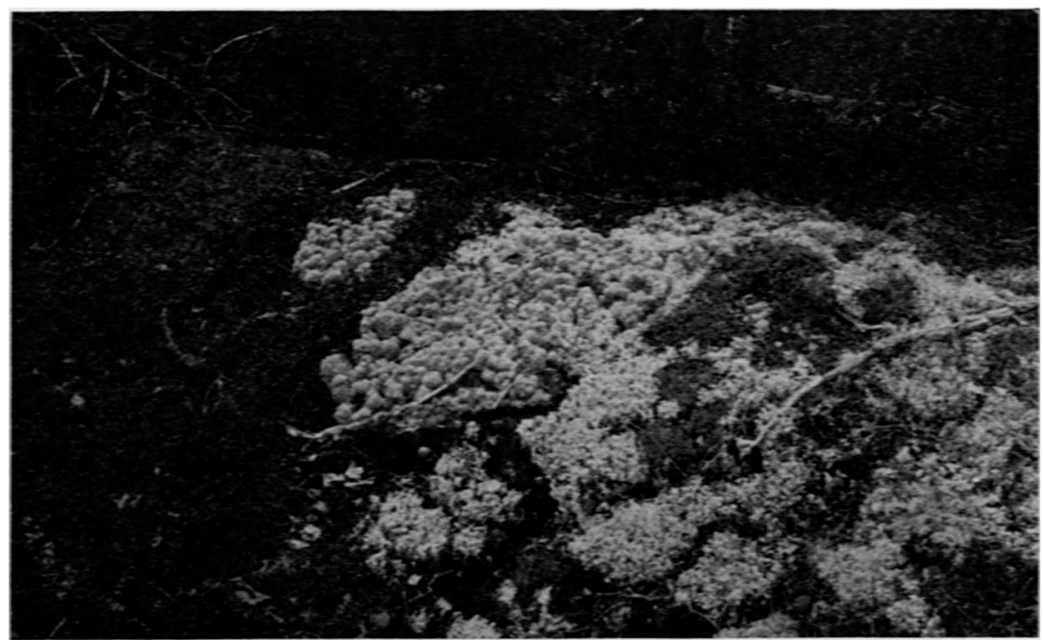

FiG. 21. -Ground cover in the jack pine-black spruce forest: the three cladonias of the heath mat (right), $C$. rangiferina, $C$. sytoatica, $C$. alpestris, invaded by the climax forest moss Calliergon Sckreberi (left).

finally smothering them to death. Calliergon Schreberi, which among the forest mosses endures the driest conditions, is the most important of these (fig. 2r). This species remains the most important element in the herbaceous vegetation throughout the intermediate forest stages, and frequently after the establishment of the climax type.

Picea mariana gradually increases, and at the same time the climax trees begin to be of importance. Here too the phenomenon of telescoping is to be seen, for we seldom find an area of jack 
pine-black spruce forest that is pure; that is, where there is not present a more or less important element representing the climax stage.

The penultimate stage in the succession is quite frequently seen. The jack pine has disappeared and the black spruces are present mainly as relicts. Calliergon Schreberi has come to share its position of dominance with the more mesophytic mosses Hypnum cristacastrensis and Hylocomium proliferum; and the climax trees have assumed their characteristic relations.

b) Effect of special conditions upon the rock shore succession

The shore vegetation as we see it today has not everywhere the same aspect, and the differences that appear are explained by the operation of the two following laws.

I. The lower limit of possible forest extension is determined approximately by the upper limit of effective wave and ice work, the lake level remaining constant.-The limit varies from the water level along the sheltered coves and harbors to a height of several meters upon the shores that face the lake. It is here far above the reach of the highest waves of the growing season, since the most severe storms take place during late fall and early winter (see ADAms 4, p. 46). While depending in the main upon the size of the waves that break upon it, the position of the limit of forest extension is modified by the character of the shore. If it be rough or broken by ledges, neither waves nor ice will be projected so far as if the slope were smooth and unbroken, and the forest in the former case may thus establish itself lower. The effects of such differences may be seen by comparing figs. I5 and 27. If by reason of a gentle submarine slope or a submerged reef the waves break far from shore, the limit of forest extension may be greatly lowered.

2. The extent to which the forestable territory has been occupied at the present day depends upon the rapidity of invasion, which is governed by the character of the rock, the angle of slope, and the degree of exposure to winds.-Abundance of irregularities and crevices in the rock surface and the presence of large quantities of the products of disintegration tend to facilitate invasion, while smoothness of surface, paucity of crevices, and freedom from disintegration prod- 
ucts retard it. On a steep slope soil materials and seeds as well are washed away to a greater extent than on a gentle one. The effect of wind in opposing invasion consists in the drying out and blowing away of the small but valuable deposits of humus which accumulate upon the rocks, in the uprooting of scattered trees feebly anchored in the shallow soil, in the breaking off of those more firmly established, and in the increase of the evaporation rate.

The effects of these factors are seldom or never strictly separable, but in various combinations they result in the production of three
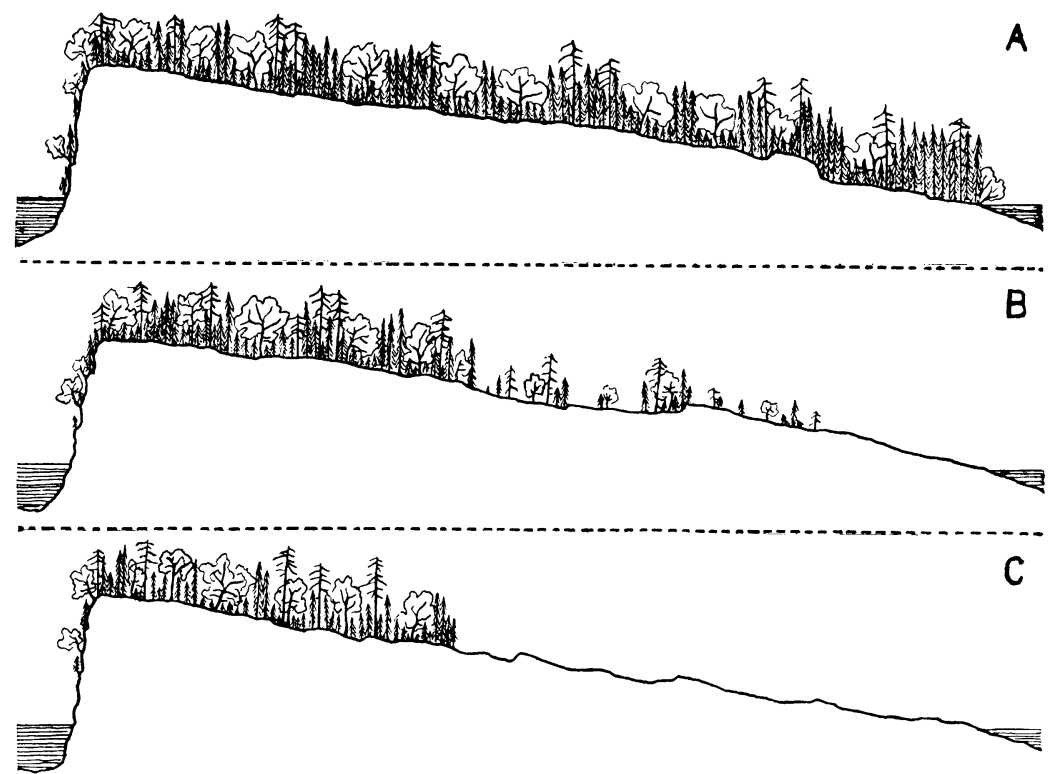

FIG. 22.-Three phases of rock shore vegetation; see text

phases of rock shore vegetation, differing from each other in respect to the position of the limit of forest extension and in the extent to which the forestable territory has been occupied. These are illustrated in the diagram (fig. 22). Both sides of the island represented are assumed to be equally exposed to wind and waves.

$A$ represents an island which is effectually sheltered from the lake storms. Shores such as these are characteristic of the inner coves and harbors of Isle Royale. Upon the gentle slope at the right the climax forest in full development has reached the water's 
edge, and a fringe of Almus crispa overhangs the bank (fig. 23). Upon the cliff at the left (fig. 22) the forest has also reached the lake level, but the trees are necessarily far apart, growing only where ledges or large crevices give them foothold. Wave action being at a minimum, the limit of possible forest extension is at the water's edge, and the conditions of surface, slope, and exposure to wind being favorable, all of the forestable territory has been occupied.

$B$ represents the phase which is perhaps the commonest upon Isle Royale, and which shows to best advantage the various stages

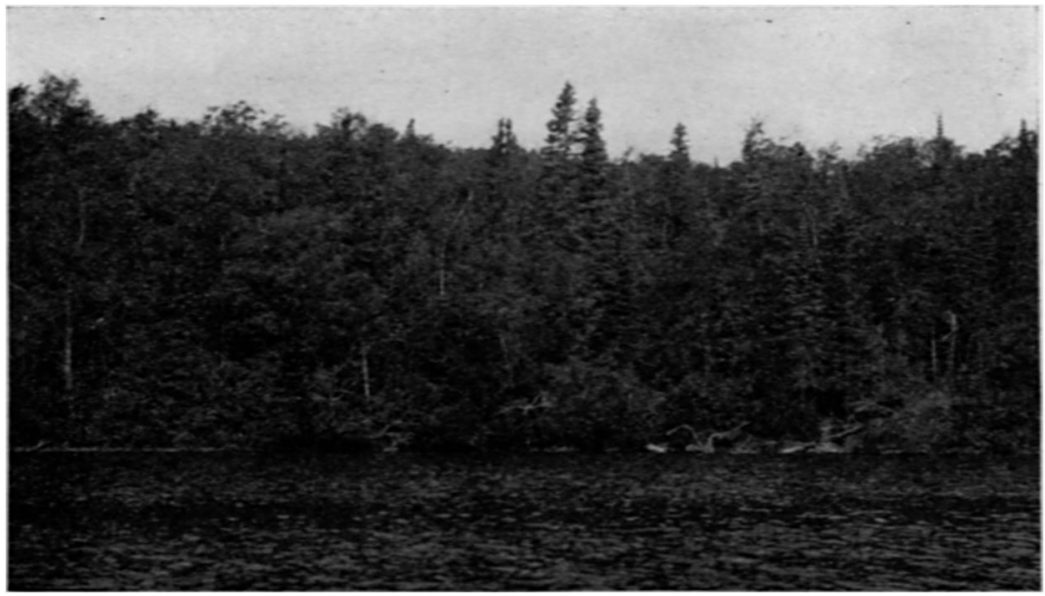

Fic. 23.-Thoroughly sheltered shore of type A: forest to the water's edge; southeast side of Blake Point peninsula.

that make the complete rock shore succession. The limit of possible forest extension may be at the water's edge or at any line above it, according to the degree of exposure. Back of this limit there is a zone where occupation has been more or less incomplete, because of one or more of the retarding influences, unfavorable character of the rock, steep slope, and exposure to winds. The manner of invasion is plainly seen upon such shores. As we pass downward from the climax forest the trees become continually sparser and smaller, and the undergrowth more xerophytic. As we go farther only scattered trees are seen, closely confined to the crevices, and 
the intervening spaces are covered with heath mat or are partially bare. The outermost pioneers of the forest may or may not have reached the limit of its possible extension. Such a shore is illustrated in fig. 24 .

Although as we pass outward the trees become less frequent and smaller, there is no corresponding decrease in age. The outermost individuals are often as old as any in the fully developed forest. The process of invasion in a given spot is a matter of much longer duration than a generation or two. Tree after tree lives its life in the same crevice and finally succumbs to the severity of the

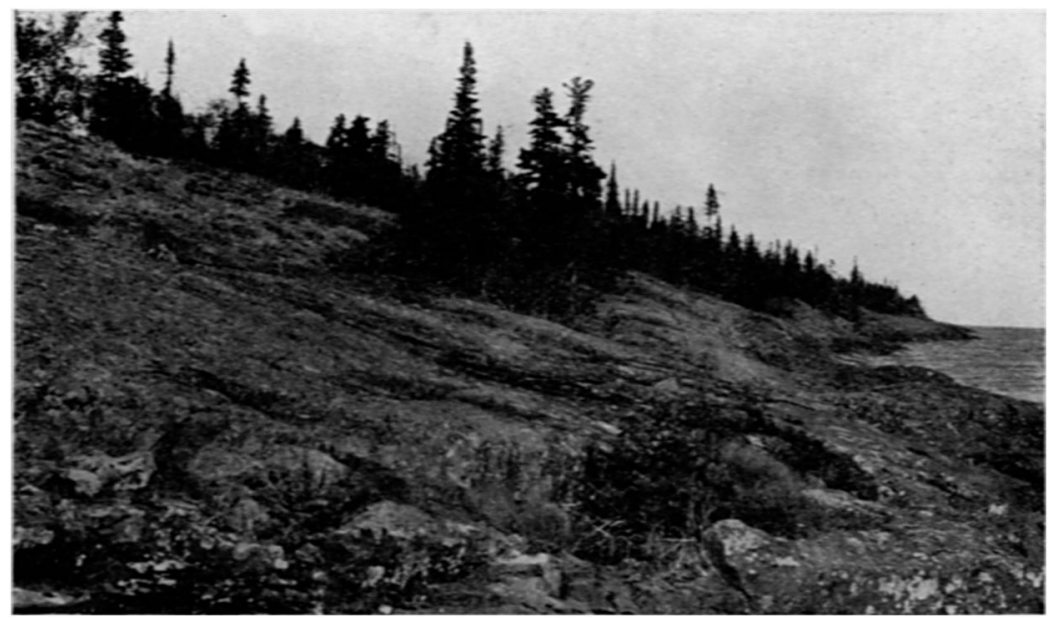

FIc. 24.-Shore of type B: gradual invasion; island near Blake Point

conditions, each contributing toward the development of the future forest only the small remnant of humus resulting from its decay that is not blown or washed away. Through successive generations the number of individuals living at the same time slowhy increases, until the assemblage of trees attains the character of true forest.

Certain of the larger rock openings upon the forested ridges, now $20 \mathrm{~m}$. or more above the water, have not yet lost their resemblance to the shores, in spite of the dozens of centuries that have passed since the lake stood at their level. Such an opening (Sec. 
33, T. 67 N., R. 33 W.) is shown in fig. 25 , and the extraordinary likeness to the shore illustrated in fig. 24 will at once be evident.

An especially interesting feature of this locality is the fact that just below the opening and extending to the water's edge of Tobin's Harbor is an area of climax forest of unusual beauty. The explanation of this is found in the physiographic history of the island. When the area of the present rock opening was actual shore the waves of the open lake broke upon it. As the water level subsided the ridge of Scovill Point appeared, affording full protection to the

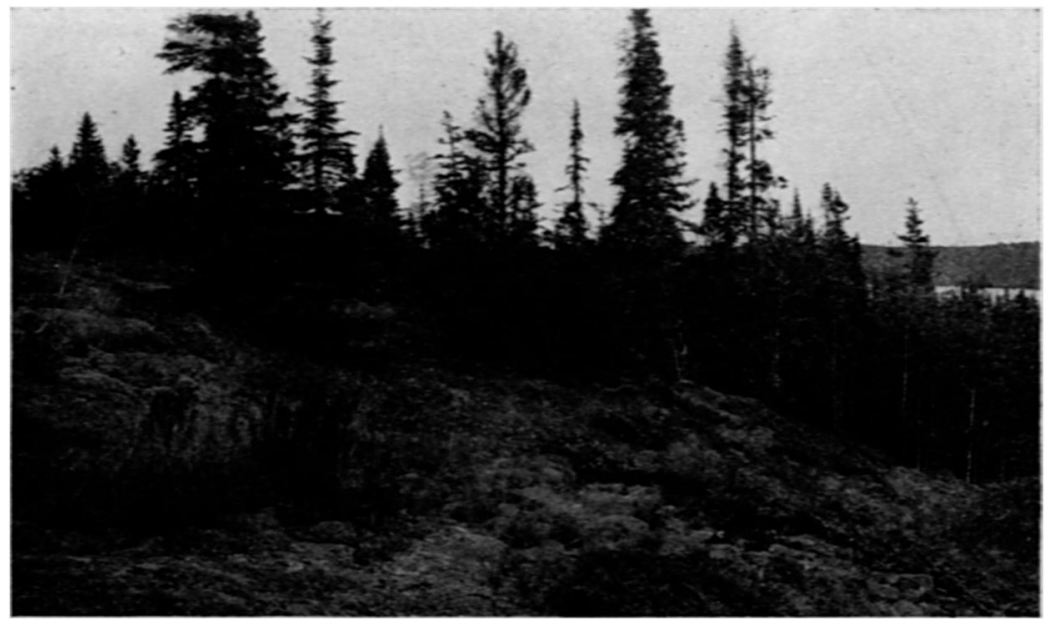

Fic. 25.- Rock opening on the southeast slope of the Greenstone Range near Tobin's Harbor: when Scovill Point (right, in the distance) was submerged, this was a shore area exposed to the open lake; note likeness to fig. 24 .

new shore area along the northwest side of Tobin's Harbor. Upon this latter, protected from both waves and wind, and receiving all the soil materials washed down from the slope above, invasion went on rapidly, resulting in the speedy establishment of the climax forest. The area higher up, exposed to the full force of the winds sweeping in from the lake across Scovill Point, still lingered in the early stages of the succession.

QUADRAT 7 (fig. 26) was located in the large rock opening described above. The likeness is so great that it may be taken also as representing shore conditions of type $B$. The surface of the 
rock was considerably disintegrated, and on areas not covered by the heath mat bore a rich lichen vegetation, the most important species, as usual in the late lichen stages, being the large cladonias. In the heath mat Juniperus communis var. depressa was dominant,

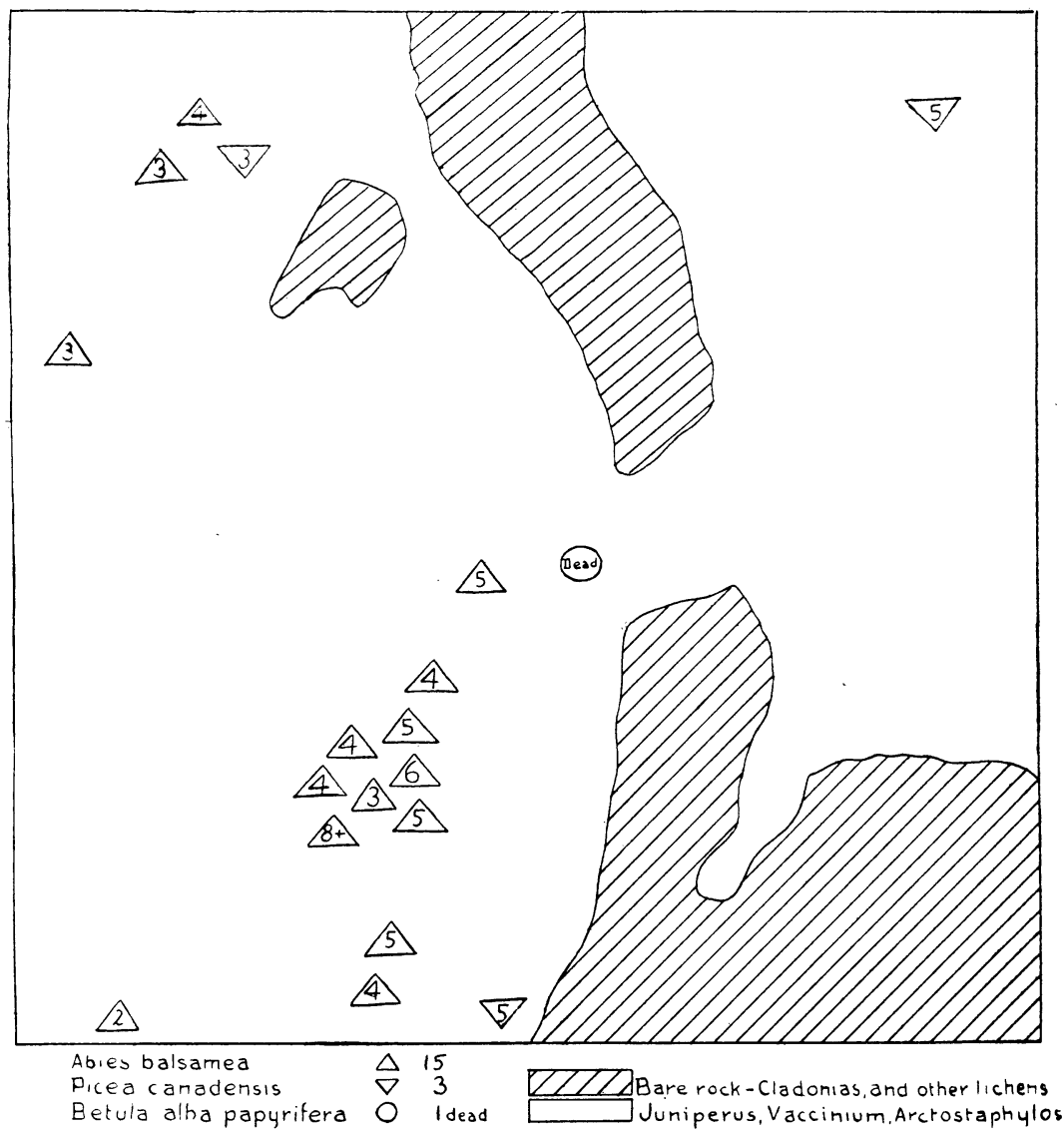

Fig. 26.-Quadrat 7: in same rock opening as fig. 25; also illustrates shore conditions of type $B$; for explanation of symbols see fig. 6 .

and Juniperus horizontalis, Vaccinium pennsylvanicum, Arctostaphylos Uva-ursi, and Calliergon Schreberi shared in its composition. Crevice plants were frequent and forest herbs occurred sparingly. Undrained depressions were filled with Aulacomnium palustre (L.) Schwaegr. and Scirpus atrocinctus Fernald. These 
in earlier times may have been rock pools. Turning to the trees, we find representatives of the three climax species and no others in this particular spot. There is thus no xerophytic forest stage here, although near by scattered individuals of Pinus Banksiana, Picea mariana, Populus tremuloides, and Thouja occidentalis were noted. Balsam, the most abundant tree of the climax forest, is even here the dominant species, and this is true of the rock shores in general. None of the trees have attained great age, 50 years being the average. The rate of growth was found to vary greatly,

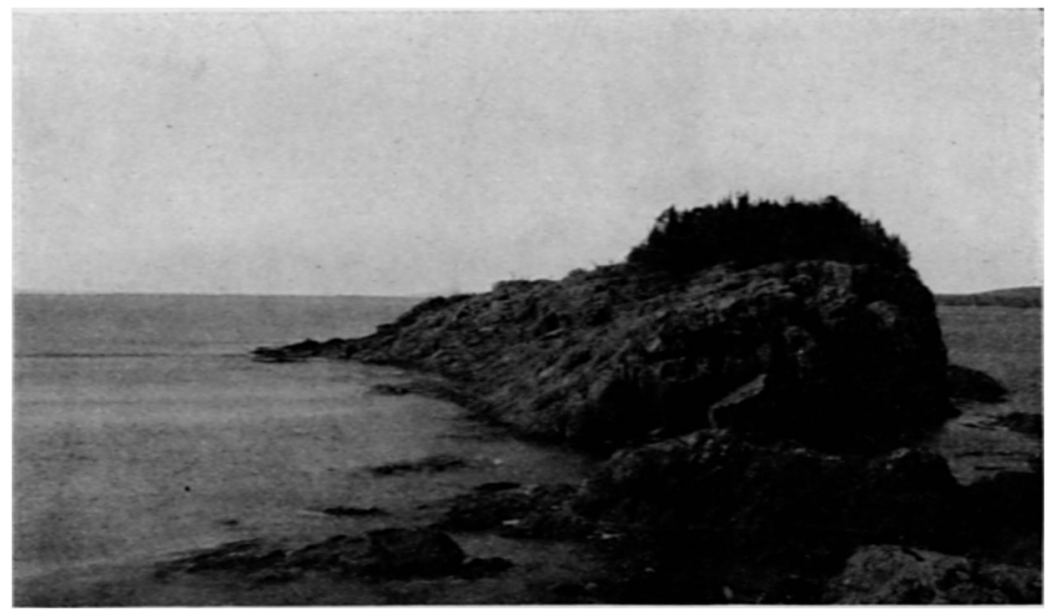

FIG. 27.-Shore of type $C$ : limit of forest extension very high, due to exposure and smoothness of slope; note abrupt transition from bare shore to forest; one of the islands bounding Rock Harbor on the southeast.

those happily situated in regard to soil, moisture, and competition having wider rings than the less favored ones. In the rather close group below the center of the quadrat, due to a crevice, suppression was already evident, a few individuals, most of them slightly older than the others, being large and well formed, while the rest were small and stunted. Occasional standing dead trunks and frequent decayed logs remained as evidence of former generations.

$C$ (fig. 22) represents the third type of shore, which is common along the most exposed portions of the southeast coast (fig. 27). The distinctive feature is the abruptness of the transition from 
the nearly bare rock surfaces on which the early lichens and crevice plants are almost the only vegetation, to the climax forest in its full development. Intermediate stages are often entirely lacking. The causes that bring about this abrupt transition are as follows. On account of the immediate proximity of the open lake the limit

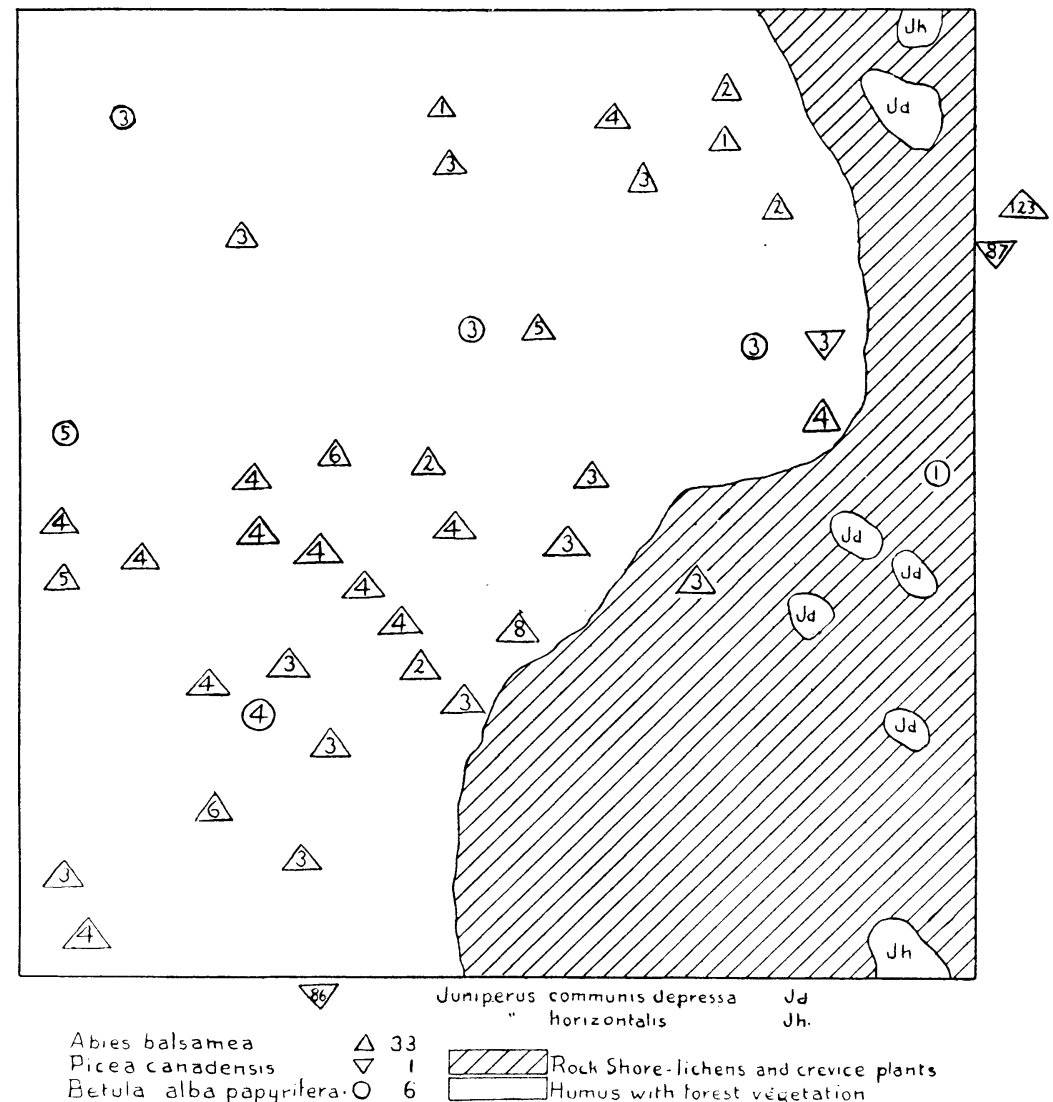

FIg. 28.-Quadrat 8: located on island illustrated in fig. 27; for explanation of symbols see fig. 6 .

of possible forest extension is very high. Above this line invasion has been sufficiently rapid to bring about the development of the climax forest upon the whole of the forestable territory. The intermediate stages have been "pinched out," as it were, by the advance of the climax forest against the impregnable barrier of the waves and ice. 
A small portion of such a shore is shown in quadrat 8 (fig. 28). It was located on a small island of the outer row (Sec. 35, T. 67 N., R. 33 W.), the same that is shown in fig. 27. The line of demarcation between forest and shore is here more definite than usual, being emphasized by the presence of a slight inward-facing cliff which affords some degree of protection to the area behind it. The shore portion of the quadrat is in a rather early stage of development, the only indication of future mat formation being the patches of the two junipers shown upon the diagram, and a few scattered plants of Arctostaphylos and Vaccinium pennsylvanicum in the crevices. The forested portion might have been taken as an excellent example of the climax type. A striking feature is the zone bordering the shore area thickly peopled with young trees, mostly balsams. This is a consequence of many windfalls, resulting from excessive exposure. The spruce and balsam just outside the quadrat on the lakeward (right) side show the tenacity with which trees occasionally persist under the severest conditions, if deeply and firmly anchored in crevices. These were low scraggy individuals, very small in diameter considering their age, being respectively 8.75 and $7.5 \mathrm{~cm}$. thick, and 87 and 123 years old.

c) Possible differences in the rock shore succession during the early history of Isle Royale

It must not be understood that the processes which are going on now are necessarily exactly like those that have been in operation during previous periods of the island's history. Many species, now of considerable importance, doubtless arrived upon the island long after its first emergence, and without these the balance of power may have been very different. There is no reason, however, for supposing that in their essential features the successions of the past have differed greatly from those of the present. A suggestion of what the earliest vegetation may have been, at the time when Isle Royale was merely a line of reefs barely above the surface of Lake Duluth, was obtained from a study of Gull Islands, $13 \mathrm{~km}$. northeast of Blake Point. There appeared some surprising differences from the normal rock shore succession as seen upon Isle Royale itself, and the effect of the animal life upon the flora was noteworthy. 
Gull Islands.-These are a line of rocky knobs rising I.5-12 m. above the surface of the water. They are projecting points of the Greenstone Ridge which disappears under the water at the northeast end of Isle Royale, reappears in Passage Island, and again here.

They are steep-sided in the main, and at one point on the northwest side of the largest islet there is a small shingle beach. As the name indicates, the islands are favorite haunts of the herring gulls, which congregate and breed here in enormous numbers. They are accompanied by many smaller birds and by untold millions of flies and gnats, evidently living upon the decaying animal matter, which is abundant and offensive.

The vegetation was found to be a strange mixture of shore and forest plants, the latter in spite of the bareness of the islands including some that habitually grow in deep shade. There were also other species which belonged to neither category. Wherever conditions favored accumulation, humus was deep and seemed to be composed largely of the remains of Calamagrostis canadensis, the most abundant species upon the islands. In some places this grass formed a thick rank growth, flowering abundantly. Over large areas there was merely a short turf, and in many places the humus was entirely bare, doubtless kept so by the gulls in their domestic operations. With Calamagrostis and forming a thicketlike growth was found Pyrus americana, and this was the only tree upon the islands. It was most abundant upon the upper part of the beach mentioned above, where a few specimens were noted that were $4 \mathrm{~m}$. high and I. $5 \mathrm{dm}$. in diameter (fig. 29). There were more dead specimens than live ones, and the living showed the effects of the hard conditions in yellow and curled foliage and dead branches. Fruit was borne abundantly. Other shrubs that formed a part of the thicket were Salix phylicifolia L.; Cornus stolonifera Michx. (red osier dogwood); Ribes prostratum L'Her (fetid currant), fruiting in wonderful abundance; $R$. oxyacanthoides L. (prickly gooseberry); Rosa acicularis Lindl. var. Bourgeauiana Crépin; Rubus idaeus L. var. aculeatissimus (C. A. Mey.) Regel \& Tiling (red raspberry), abundant; Sambucus racemosa L. (redberried elder); Taxus canadensis Marsh (ground hemlock), frequent, forming a low matted yellowish growth partially protected 
by other shrubs; most surprising of all, Fatsia horrida (Sm.) B. \& H. (devil's club), about six specimens with curled and yellow leaves, but all flowering.

In all, 26 species were listed, and of these only 5 are characteristic shore plants; Io were species found ordinarily in the climax forest, but growing here with more or less success in spite of the severe conditions. The way in which many of the plants reached the island is suggested by the fact that ro out of the 26 bear more or less edible berries. Birds have evidently been important agents in determining the composition of the flora of Gull Islands.

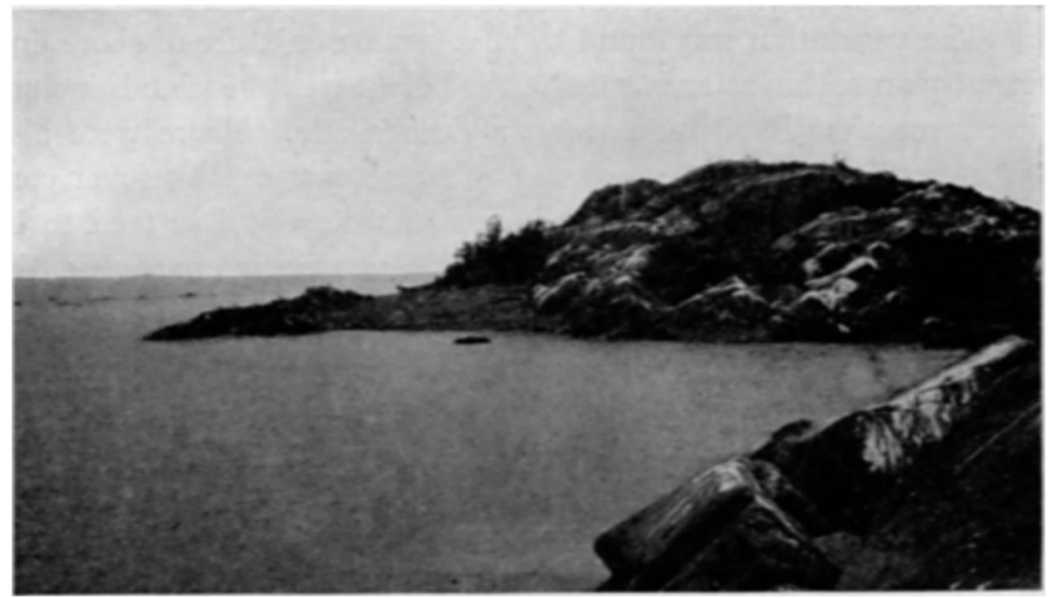

Fig. 29. - One of the Gull Islands: a small shingle beach with stunted mountain ash; with this grew a few plants of devil's club (Fatsia).

Such a type of vegetation as exists today upon these rocks may well have been the first to occupy the summits of the Isle Royale ridges when they first emerged from Lake Duluth. As the area of the island increased, and more and more species became established upon it by various means, the vegetation of the shores and the successional processes concerned therein became gradually like those of today.

III. The beach succession

a) Extent, situations, and materials of the beaches.-Beaches are numerous but not extensive upon Isle Royale. There are many 
miles of rocky coast absolutely unbroken by beaches of any kind. Wave erosion at the present lake level has not yet produced an irregular coast line, in the reentrants of which they might develop, nor has it furnished abundance of sand, gravel, and shingle for their building. The general steepness of the shores is another unfavorable feature. Such as are present occur in the bays and coves, most of which are due not to wave erosion but to the original configuration of the rocks. The fragments eroded from the bold cliffs and headlands near by are swept into these reentrants and come to rest there in the comparatively quiet water. Most of the beaches are of limited extent, but at the head of Siskowit Bay there are two magnificent stretches, separated by Senter Point, which have a total length of $2 \mathrm{~km}$. The materials range from fine sand to coarse shingle, the larger sizes being by far the commoner. Back from many of the present beaches extend similar accumulations which were made when the water level stood higher than now, and formations identical in character occur at various levels upon the ridges.

b) Vegetation.-From their nature, beaches occupy situations that are more or less protected from the full force of waves and ice, and usually from wind also by reason of neighboring headlands. As compared with the rock shores they thus provide favorable opportunity for invasion by plants. The limit of possible forest extension, as in the case of the rock shores, varies with the effective reach of waves and ice, but is never high. Below this limit the materials are frequently moved about by the waves, and all vegetation except annuals is manifestly impossible. Even lichens must be destroyed by the movement and friction. Above the limit of the waves, where the fragments are not disturbed, conditions are particularly favorable for invasion. If the material is fine a soil is already present, if coarse there is opportunity for the accumulation of soil in the interstices of the shingle. In the latter case water drains off too rapidly, but as the openings become filled, this fault is gradually corrected.

Because of the favorable conditions enumerated above, the climax forest in most cases has already advanced to its limit of possible extension. Very often a bank of solid humus, formed 
during long ages of forest growth, marks the upper boundary of the beach. The transitional stages have thus been pinched out, and opportunities for their investigation are therefore scanty.

Where the forest ends most abruptly a line of Alnus crispa commonly fringes it (fig. 30). Where the transition is slightly more

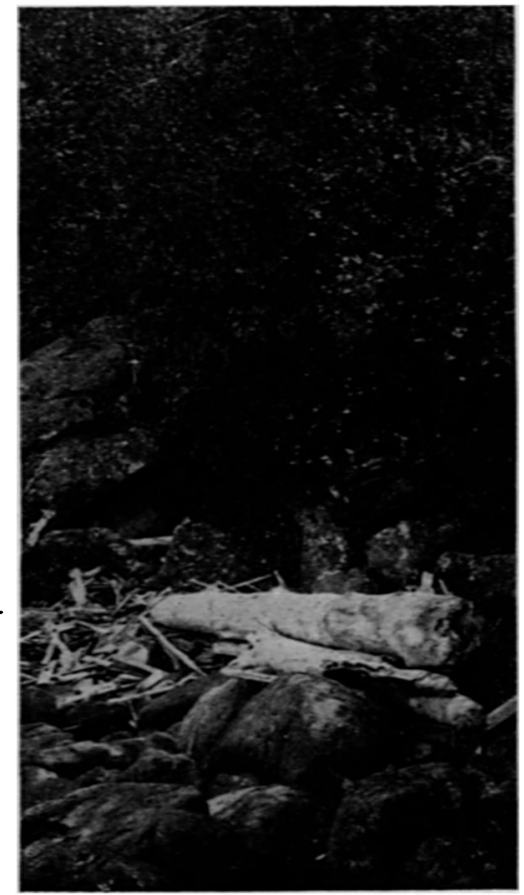

FrG. 30- Upper limit of shingle beach on the northwest side of the Blake Point peninsula: note lange size of material; Alnus crispa fringing the forest. gradual there are suggestions of intermediate stages. Out among the shingle are found scattered herbs: Equisetum arvense $\mathbf{L}$. (horsetail), Epilobium angustifolium L. (fireweed), Deschampsia caespitosa (L.) Beauv. (hair grass). Rubus triflorus Richards (dwarf raspberry) often trails over the stones for many decimeters. A more important group is made up of low shrubs, among which Rubus idaeus var. aculeatissimus (red raspberry), Diervilla Lonicera Mill (bush honeysuckle), Rosa acicularis Lindl., Physocarpus opulifolius (L.) Maxim. (ninebark), and Rubus parviflorus Nutt. (whiteflowered raspberry) are most prominent. Behind these come the tall shrubs, Alnus crispa most important, and also Corrus stolonifera and several species of Salix. No instance of actual transition into the climax forest was observed, but it probably follows immediately after the tall shrubs.

palo alto, Caltrorkia 